\title{
Effects of silicon surfactant in rigid polyurethane foams
}

\author{
H. $\operatorname{Lim}^{2}$, S. H. Kim 1 , B. K. Kim $1 *$ \\ ${ }^{1}$ Department of Polymer Science and Engineering Pusan National University, Busan 609-735, Korea \\ ${ }^{2}$ Korea Polyol Co., Ulsan 680-090, Korea
}

Received 28 November 2007; accepted in revised form 29 January 2008

\begin{abstract}
The rigid polyurethane foams (RPUFs) have been fabricated from high functional crude 4,4'-di-phenylmethane diisocyanate (CMDI) and polypropylene glycols (PPGs) for a wide range of surfactant concentration with an environmently friendly blowing agent (HFC $365 \mathrm{mfc}$ ). Cream time, gel time, and tack-free time increased with the addition of surfactant. Foam density decreased rapidly to a minimum at $0.5 \mathrm{pphp}$ (part per hundred polyol) surfactant due to the increased blowing efficiency with surfactant. Surface tension rapidly decreased to an asymptotic value at 2 pphp surfactant. In accordance with this, cell size decreased and closed cell content increased rapidly to constant values at low surfactant concentrations $(<1 \mathrm{pphp})$. The decrease of cell size was accompanied by the decrease of thermal conductivity to give a linear relatiohship between the two implying that the series model of heat transfer is applicable.
\end{abstract}

Keywords: thermal properties, rigid polyurethane foam (RPUF), cell structure, compression strength, thermal conductivity

\section{Introduction}

Polyurethanes (PUs) are used as coatings, adhesive, sealants, elastomers (CASE), and fibers as well as flexible, semi-rigid and rigid foams [1-3]. Among them, rigid PU foams (RPUFs) have closed cell structure with low thermal conductivity, high compression strength, low density, high strength-toweight ratio, and low moisture permeability [2-4]. Consequently, RPUFs finds such applications as insulations of refrigerators, freezers, piping, tanks, ship building, and LNG cargos [5-8].

The foaming can be done by one shot or two shot methods. In one shot method, all materials are put into a mixing cup and mixed homogeneously before they are poured into a mold. In the two shot method, isocyanate is added to the mixture at the second stage. The foaming can be carried out with a physical blowing agent, chemical blowing agent, or with a mixture of the two [5]. In physical blowing, reactions between isocyanate and polyol produce polyurethane linkages with the emission of heat of reaction. Then, the blowing agent vaporizes and the gas trapped in the closed cells of the foam [9]. Typically, thermal conductivity of the blown gas is very low. This, with small closed cell structure gives extremely low thermal conductivity of the RPUFs. In chemical blowing, water (most widely used blowing agent) reacts with isocyanate to form unstable carbamic acid which immediately decomposes into an amine and carbon dioxide [2, 10, 11]. Recently, many of the conventional blowing agents such as monofluorotrichloromethane (R11) and difluorodichloromethane (R12) have been suggested to contribute to the depletion of the stratospheric ozone layer and the use has been regulated in many countries. Consequently, the use of environmentally friendly blowing agents has become an important and urgent issue in the synthesis of polyurethane foam [12-14]. Water can in part replace such environmentally hazardous blowing

*Corresponding author, e-mail: bkkim@pnu.edu

(C) BME-PT and GTE 
agents. However, the excessive use of water causes a negative pressure gradient due to the rapid diffusion of $\mathrm{CO}_{2}$ through the cell wall causing cell deformation $[2,3,15,16]$.

The kinetics of RPUF formation mainly depends on the rates of blowing and gelling reactions, which on the other hand are respectively governed by an amine and a tin catalyst $[4,6]$. On the other hand, the properties of the foam mainly depend on the type of polyol such as functionality and hydroxyl value, and type and amount of surfactant, and blowing agent. To reinforce the foam, composites with particle, clays and fiber have been considered [17-21].

As far as the present authors are concerned, systematic investigations of the effects of surfactant on various properties of RPUF are sparse, perhaps except those blown with water [7, 22].We synthesized various types of RPUFs from CMDI and polypropylene glycols (PPGs) with an environmentally friendly physical blowing agent, viz. HFC $365 \mathrm{mfc}\left(\mathrm{CF}_{3} \mathrm{CH}_{2} \mathrm{CF}_{2} \mathrm{CH}_{3}\right)$, with a potential target application of insulation panel of LNG cargo where high compression strength as well as thermal insulation is highly desired. The effects of silicon surfactant concentration on the performances of the foams have been extensively analyzed in terms of reactivity, cell morphology, surface tension, and mechanical and thermal properties of the foams.

\section{Experimental}

\subsection{Raw materials}

Two types of PPG having hydroxyl value (OHV, $\mathrm{mg} \mathrm{KOH} / \mathrm{g}$ of sample) of 450 and 400 (HR-450P and KR-403) were provided by Korea Polyol Co (Korea). The CMDI was provided by Huntsman (Suprasec-5005), HFC 365mfc by Solvay Chemicals (Belgium), and Polycat-8 as foaming catalyst by Air Products. Silicon surfactant (B 8404) known to augment the closed cell content thus providing improved thermal insulation was provided by Goldschmidt. PPGs were dehydrated before use at $90^{\circ} \mathrm{C}$ for $24 \mathrm{~h}$ in a vacuum oven. Other chemicals were used as received.

\subsection{Preparation of samples}

The rigid foams were synthesized by one shot method. All raw materials were first put into a mix-
Table 1. Formulation to synthesize the RPUFs

\begin{tabular}{|c|c|}
\hline Components & Compositions [g] \\
\hline HR-450P & 80 \\
\hline KR-403 & 20 \\
\hline Polycat- 8 & 1 \\
\hline B 8404 & Variable $(0,0.2,0.5,1.0,2.0,5.0$ pphp $)$ \\
\hline HFC 365mfc & 10.1 \\
\hline CMDI & 116.9 \\
\hline Index & 110 \\
\hline
\end{tabular}

HR-450P; hydroxyl value 450, Initiator; glycerin and sucrose + PO KR-403; hydroxyl value 400, Initiator; toluene diamine + PO

ing vessel (Utra-Turrox T-50, Ika-Werke) and mixed for $30 \mathrm{~s}$ at $7000 \mathrm{rpm}$. Then the mixtures were discharged to an open mold $(200 \times 200 \times 200 \mathrm{~mm})$ and the foam cake was cured for 1 week at room temperature. The NCO index (isocyanate equivalents/polyol equivalents) was fixed at 1.10. The basic formulations are given in Table 1.

\subsection{Characterizations}

Density of the foam was measured according to ASTM D 1622 with sample size of $30 \times 30 \times 30 \mathrm{~mm}$ (width $\times$ length $\times$ thickness), and an average of at least five measurements was taken to report. The density distribution [\%] was calculated according to $100 \times$ (maximum density-minimum density)/average density.

The closed cell content was determined by an air pycnometer following ASTM D 2850 with specimen dimension $50 \times 50 \times 25 \mathrm{~mm}$. Thermal conductivity was measured using HC-074 (Laser Comp) according to ASTM C 518. The cell morphology was observed under a scanning electron microscope (SEM, HITACHI S3500N). Samples were cryogenically fractured in liquid nitrogen and gold sputtered before they were scanned in the free rising direction. Mechanical properties at room temperature were measured using a Universal Testing Machine (Ametek, Lloyd). Compression strength was determined by ASTM D 1621 at a crosshead speed of $3.0 \mathrm{~mm} / \mathrm{min}$ with the sample dimension of $30 \times 30 \times 30 \mathrm{~mm}$ [7]. The force required for $10 \%$ deformation based on the original thickness has been taken as the compression strength of the foam. The surface tension was measured using Tensiometer K 100 (Kruss) according to ASTM D 1331 based on bubble pressure. 
Table 2. Reactivity

\begin{tabular}{|l|c|c|}
\hline & $\begin{array}{c}\text { Without silicone } \\
\text { surfactant }\end{array}$ & $\begin{array}{c}\text { With silicone } \\
\text { surfactant }\end{array}$ \\
\hline Cream time [s] & 57 & $60 \sim 62$ \\
\hline Gel time [s] & 180 & $198 \sim 206$ \\
\hline Tack-free time [s] & 220 & $240 \sim 250$ \\
\hline
\end{tabular}

\section{Results and discussion}

\subsection{Kinetics of foam formation}

Kinetics of the foam formation is followed by the cream time, gel time and tack-free time $[4,6,10]$. The cream time corresponds to the start of bubble rise and hence color of the mixture becomes creamlike from dark brown due to the introduction of bubbles. Gel time is the starting point of stable network formation by intensive allophanate crosslinks as well as urethane. At the tack-free time, the outer surface of the foam loses its stickiness and the foam can be removed from the mold. Table 2 shows that cream time, gel time and tack-free time increase with increasing surfactant concentration, implying that the surfactant reduces diffusion across the interfaces. The PPGs are incompatible with CMDI and the reaction mixtures are heterogeneous. For this reason surfactants should carry high surface activity to act as a nucleation supporter and good emulsifying ability for the raw materials and blowing agents [3].

\subsection{Foam density and density distribution}

Density is a most important parameter to control the mechanical and thermal properties [23] of closed cell foams $[2,3]$. With increasing surfactant concentration, foam density decreases asymptotically to a small minimum at $0.5 \mathrm{pphp}$, beyond which the increase is marginal (Figure 1). Similar results were obtained by Krupers et al. [22] who reported that average foam height increases, i.e., density decreases with the addition and increasing amount of fluorosurfactant. This implies that the blowing efficiency is increased with the addition of surfactant by supporting the ability to create nuclei and augmenting the stability of the foams. It seems that the surfactant in excess is not interposed at the interfaces and rather increases the heterogeneity of the system.

Foam density decreases along the bubble rising direction i.e., from bottom to top due to the gravity
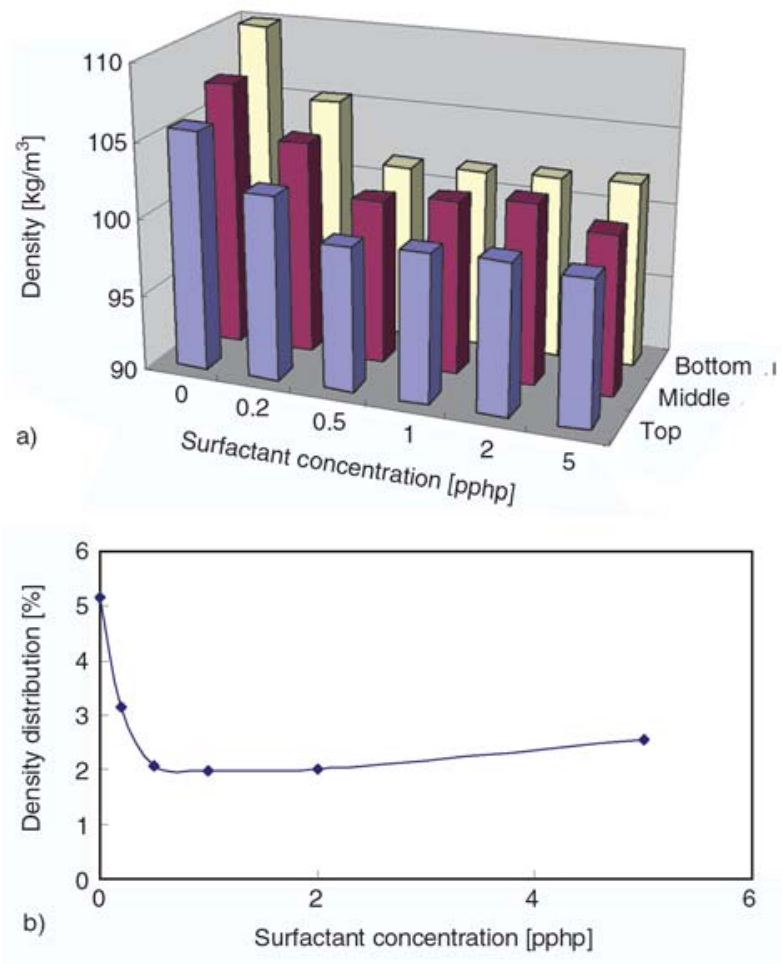

Figure 1. Densities (a) and density distributions (b) of the RPUFs vs. surfactant concentration

effect giving rise to great compression at bottom. The density distribution along the rise direction also shows similar surfactant dependence as density, i.e., the density variation shows a minimum at 0.5 pphp surfactant.

\subsection{Surface tension and cell morphology}

The exothermic heat of reaction causes the supersaturation of the reactive mixture resulting in phase separation into gas, followed by diffusion into the nuclei which are small air bubbles entrapped during the mixing of raw materials [24]. Then the nuclei grow into bubbles and spherical cells by adopting

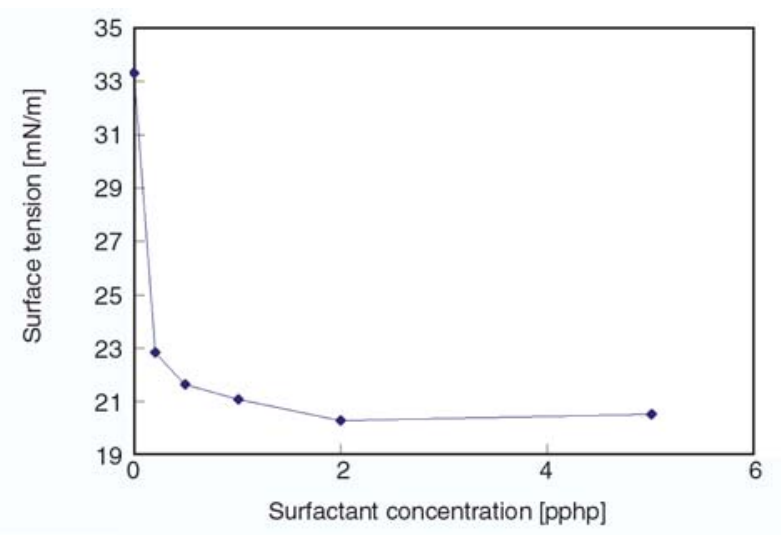

Figure 2. Surface tensions of the RPUFs vs. surfactant concentration 
more gases or by coalescence with neighboring ones. As the blow ratio increases the spherical bubbles are eventually separated by the cell membrane and become polyhedral.

The surface tension of the polyol for various surfactant concentrations are shown in Figure 2 which shows that the surface tension decreases rapidly to an asymptotic value at $2 \mathrm{pphp}$. The asymptotic value of surface tension is approximately $2 / 3$ of the surfactant-free value.

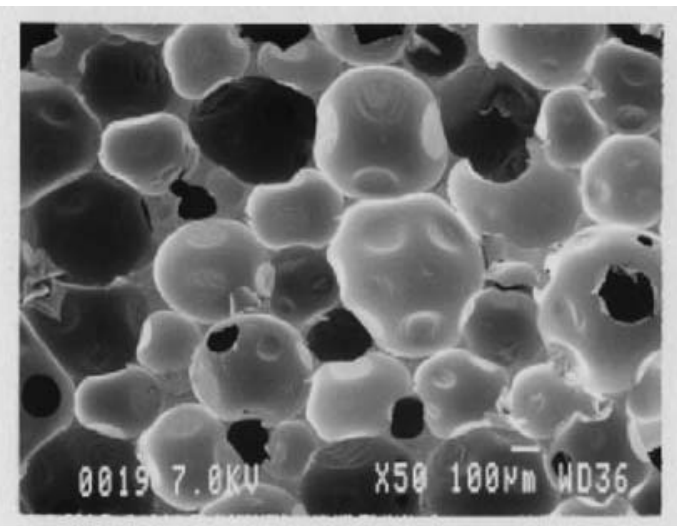

a)

0 pphp

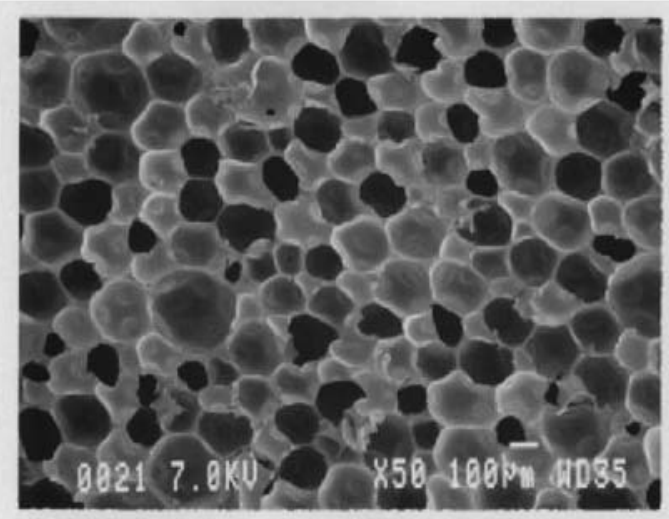

c)

$0.5 \mathrm{pphp}$

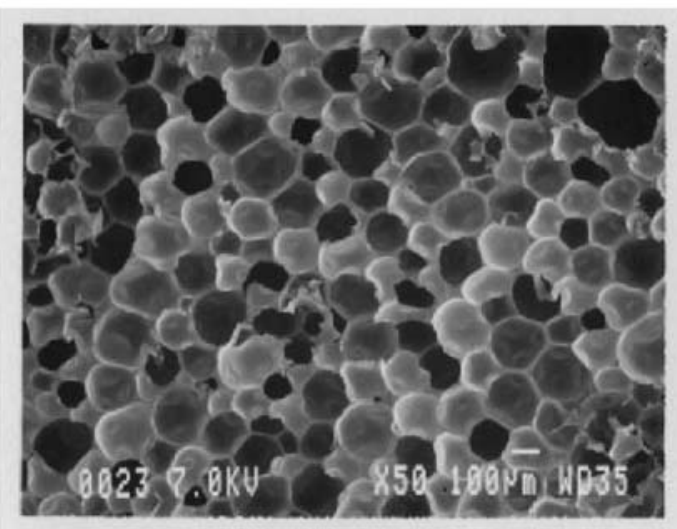

e)

$2.0 \mathrm{pphp}$
SEM micrograph shows that the foams consist of cells of spherical and polyhedral shape (Figure 3). Cell size (Figure 4) decreases rapidly to an asymptotic value of about $140 \mu \mathrm{m}$ with the addition of surfactant. Cell size as small as $100 \mu \mathrm{m}$ was also reported with fluorosurfactant [22]. On the other hand, the closed cell content (Figure 5) increases asymptotically with increasing surfactant concentration due to the decrease in surface tension. The increase of closed cell content is accompanied by

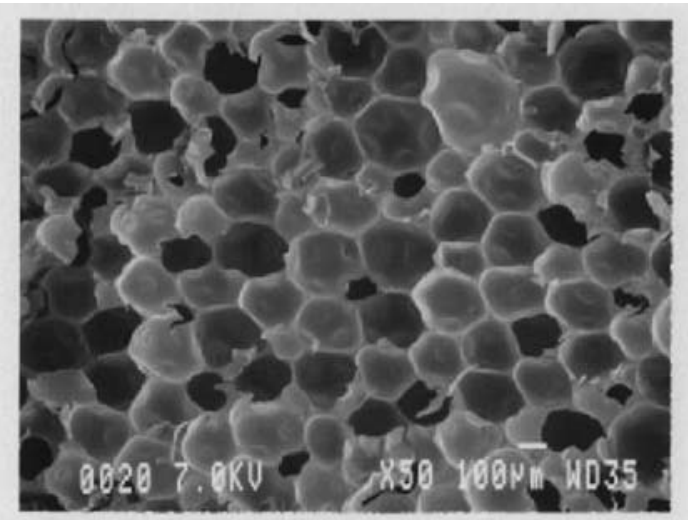

b)

$0.2 \mathrm{pphp}$

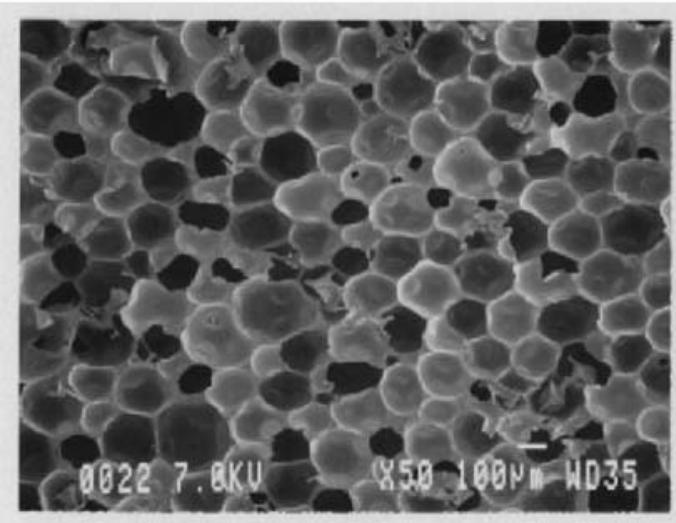

d)

$1.0 \mathrm{pphp}$

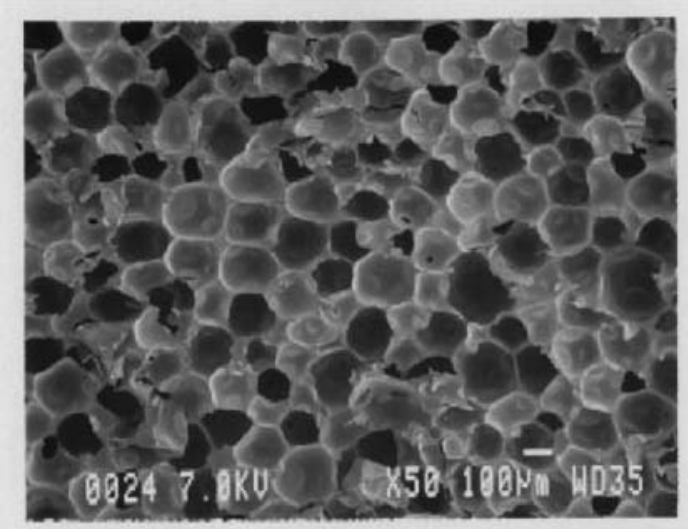

f)

5.0 pphp

Figure 3. SEM micrographs of the RPUFs vs. surfactant concentration 
Table 3. Porosities of the RPUFs

\begin{tabular}{|c|c|c|c|c|c|c|}
\hline Surfactant [pphp] & $\mathbf{0}$ & $\mathbf{0 . 2}$ & $\mathbf{0 . 5}$ & $\mathbf{1}$ & $\mathbf{2}$ & $\mathbf{5}$ \\
\hline Porosity [\%] & 89.6 & 89.2 & 90.0 & 90.3 & 89.6 & 89.7 \\
\hline Closed porosity [\%] & 63.3 & 82.8 & 84.3 & 84.7 & 84.1 & 84.6 \\
\hline Open porosity [\%] & 26.3 & 6.4 & 5.7 & 5.6 & 5.5 & 5.1 \\
\hline
\end{tabular}

Porosity was calculated using the resin density of $980 \mathrm{~kg} / \mathrm{m}^{3}$

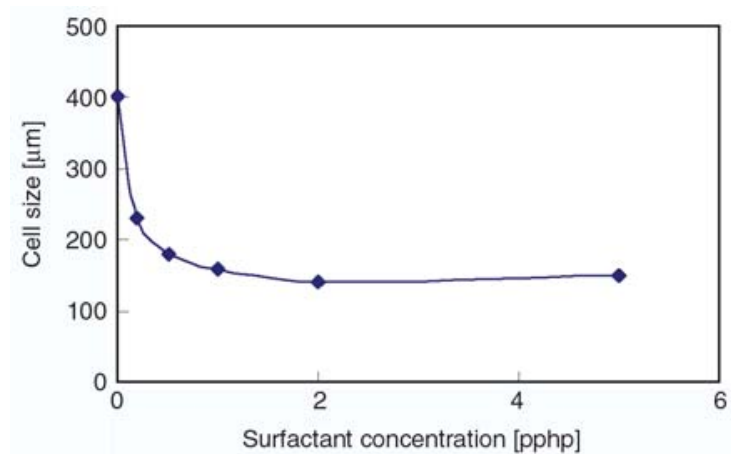

Figure 4. Cell size of the RPUFs vs. surfactant concentration

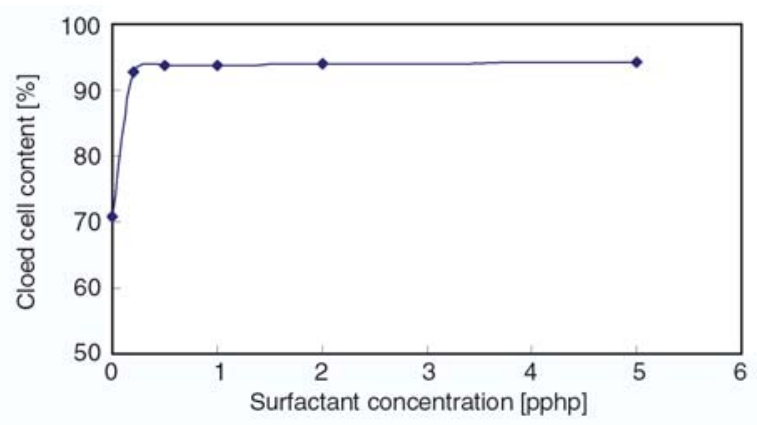

Figure 5. Closed cell contents of the RPUFs vs. surfactant concentration

the increase of closed porosity while the full porosity is kept almost constant (Table 3). This implies that closed cell content and porosity as well as the cell size are closely controlled by the amount of surfactant being added.

\subsection{Compression strength}

The compression strength is closely related to the dimensional stability of closed cell foams. As the temperature goes up, gas pressure inside the cell increases, and the pressure difference relative to the atmospheric pressure becomes great. If the foam is to be dimensionally stable under these conditions, the compression strength must be greater than the pressure rise [2]. The minimum compression strength of $0.1 \mathrm{MPa}$ is generally recommended for closed cell foam [6].
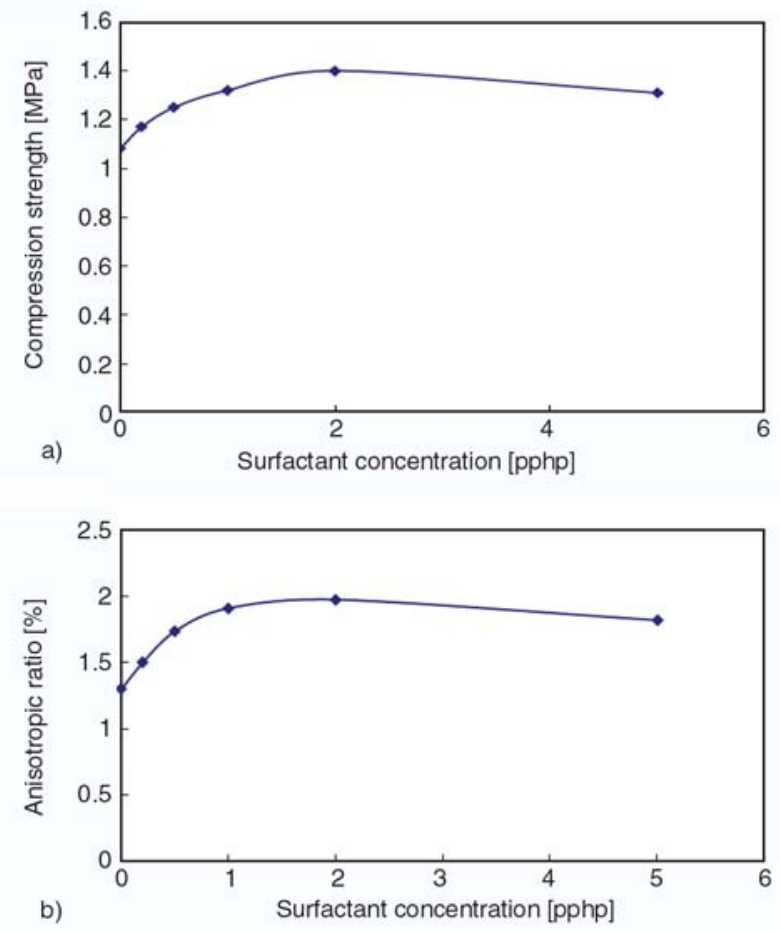

Figure 6. Compression strengths (a) and strength anisotropies (b) of the RPUFs vs. surfactant concentration

The compression strength of our foam is greater than $0.97 \mathrm{MPa}$ (perpendicular). In contrast to the density decrease, strength and its anisotropy (strength ratio of parallel to perpendicular direction) smoothly increases with increasing concentration of surfactant with a maximum at 2 pphp (Figure 6). An earlier work showed simultaneous decreases of compression strength with increasing surfactant concentration [7]. It seems that the compression strength is closely related to the closed cell content and cell size when the density variation is insignificant

\subsection{Thermal conductivity of the foam}

Heat conduction through the closed cell foams can be approximated by a series model which is composed of polymer walls and gas cells in series [25]. 
Conductive heat flux $(q)$ through the composite wall is given by Equation (1):

$$
q=\frac{\Delta T}{R}
$$

where $\Delta T$ is the temperature drop across the foam and $R$ is the conduction resistance given by the following Equation (2):

$$
R=\sum_{i=1}^{n}\left(\frac{X_{W, i}}{k_{W}}+\frac{X_{G, i}}{k_{G}}\right)
$$

Here $X_{W, i}$ and $X_{G, i}$ are the cell wall thickness and cell dimension, and $n$ is the number of polymer walls, respectively. For uniform cells, wall thickness $\left(X_{W, i}\right)$ and cell dimension $\left(X_{G, i}\right)$ are constant to give Equation (3):

$$
R=n\left(\frac{X_{W}}{k_{W}}+\frac{X_{G}}{k_{G}}\right)
$$

In the typical closed cell foam, the polymer walls occupy 3-6 volume $\%$ of the foam. In addition, the conductivity of the polymer is much greater than that of the blowing gas. So, the first term, viz. polymer wall resistance can be neglected to give Equation (4):

$$
R=n\left(\frac{X_{G}}{k_{G}}\right)
$$

The above simple analysis shows that the thermal insulation of closed cell foams increase linearly with the number of closed cells, i.e., effect of insulation increases as the cell size decreases [26].

The thermal conductivity of our foam rapidly decreases to an asymptotic value at $1 \mathrm{pphp}$ surfac-

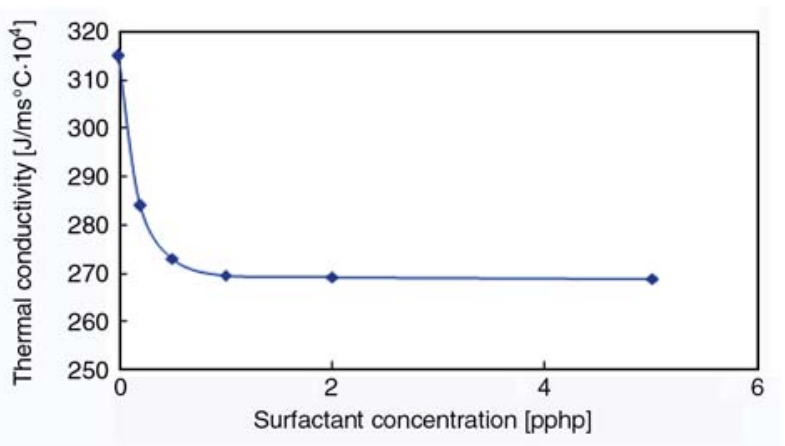

Figure 7. Thermal conductivities of the RPUFs vs. surfactant concentration

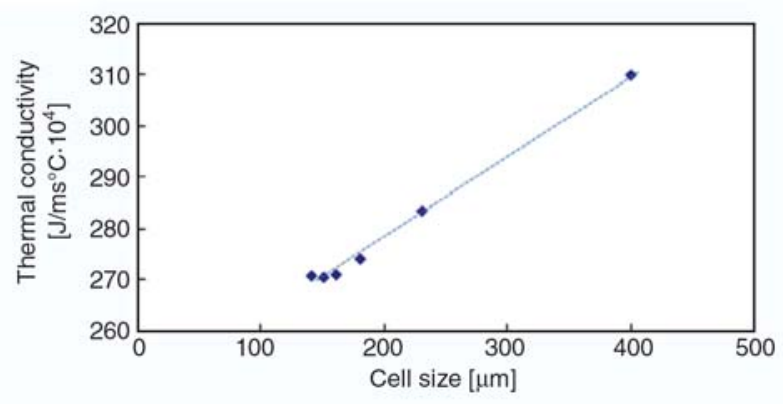

Figure 8. Thermal conductivities vs. cell size for the RPUFs

tant (Figure 7). The decrease is mainly due to the decreased cell size as analyzed above. To confirm this, the relationship between the thermal conductivity and cell size is plotted in Figure 8 which shows a straight line for a broad range of cell size. This implies that the series model is applicable where the wall resistance can be considered for small cells.

\section{Conclusions}

The RPUFs have been fabricated from CMDI and PPGs as a function of surfactant concentration with an environmently friendly blowing agent (HFC $365 \mathrm{mfc}$ ). Cream time, gel time, and tack-free time increased with the addition of surfactant due to the increased stability of reaction mixture and rising bubbles.

Foam density and density distribution decreased rapidly to a minimum at $0.5 \mathrm{pphp}$ surfactant due to the increased blowing efficiency in the presence of surfactant. Surface tension of the foam rapidly decreased to an asymptotic value at 2 pphp surfactant, implying that the reaction mixture is saturated at this concentration.

In accordance with the decreased surface tension, cell size decreased and closed cell content increased rapidly to constant values at low surfactant concentrations ( $<1 \mathrm{pphp})$ ).

The decrease of cell size was accompanied by the decrease of thermal conductivity, and a linear relatiohship between the two was held for a broad range of cell size. Simple analysis based on series model also gave the same result assuming the resistance of cell wall is negligible except the small cells. 


\section{Acknowledgements}

This research was supported by the Ministry of Commerce, Industry and Energy (MOCIE) and Korea Industrial Technology Foundation (KOTEF) through the Human Resource Training Project for Regional Innovation. BKK is also indebted to the National Core Research Center organized at PNU.

\section{References}

[1] Hepburn C.: Polyurethane elastomers. Elsevier, London (1991).

[2] Oertel G.: Polyurethane handbook. Hanser Publishers, New York (1985).

[3] Szycher M.: Szycher's handbook of polyurethanes. CRC Press, New York (1999).

[4] Singh H., Sharma T. P., Jain A. K.: Reactivity of the raw materials and their effects on the structure and properties of rigid polyurethane foams. Journal of Applied Polymer Science, 106, 1014-1023 (2007)

[5] Mondal P., Khakhar D. V.: Regulation of cell structure in water blown rigid polyurethane foam. Macromolecular Symposia, 216, 241-254 (2004).

[6] Seo W. J., Park J. H., Sung Y. T., Hwang D. H., Kim W. N., Lee H. S.: Properties of water-blown rigid polyurethane foams with reactivity of raw materials. Journal of Applied Polymer Science, 93, 2334-2342 (2004).

[7] Seo W. J., Jung H. C., Hyun J. C., Kim W. N., Lee YB., Choe K. H., Kim S-B.: Mechanical, morphologi$\mathrm{cal}$, and thermal properties of rigid polyurethane foams blown by distilled water. Journal of Applied Polymer Science, 90, 12-21 (2003).

[8] Xiao Z., Guan R., Jiang Y., Li Y.: Tensile property of thin microcellular PC sheets prepared by compression molding. Express Polymer Letters, 1, 217-225 (2007).

[9] Chai J. B., Kim B. K., Shin Y. J.: Absorption of hydrophobic fluid by polyurethane foam. Journal of Korean Industrial and Engineering Chemistry, 9, 648653 (1998).

[10] Harikrishnan G., Khakhar D. V.: Effect of monomer temperature on foaming and properties of flexible polyurethane foams. Journal of Applied Polymer Science, 105, 3439-3443 (2007).

[11] Kwon O-J., Yang S-R., Kim D-H., Park J-S.: Characterization of polyurethane foam prepared by using starch as polyol. Journal of Applied Polymer Science, 103, 1544-1553 (2007).
[12] Antolini B., Bianchi F., Bottazzi M., Careri M., Musci M.: Development and validation of novel DH-GCITMS methods for the determination of freon F-141b in formulated polyol and rigid polyurethane foam. Chromatographia, 60, 323-327 (2004).

[13] Heintz A. M., Duffy D. J., Hsu S. L., Suen W., Chu W., Paul C. W.: Effects of reaction temperature on the formation of polyurethane prepolymer structures. Macromolecules, 36, 2695-2704 (2003).

[14] Widya T., Macosko C. W.: Nanoclay-modified rigid polyurethane foam. Journal of Macromolecular Science, Part B: Physics, 44, 897-908 (2005).

[15] Kim S. H., Lim H., Song J. C., Kim B. K.: Effect of blowing agent type in rigid polyurethane foam. Journal of Macromolecular Science, Part A: Pure and Applied Chemistry, 45, 1-5 (2008).

[16] Gent A. N.: Engineering with rubber: How to design rubber components. Hanser Gardner Publications, Cincinnati (2001).

[17] Goods S. H., Neuschwanger C. L., Whinnery L. L., Nix W. D.: Mechanical properties of a particlestrengthened polyurethane foam. Journal of Applied Polymer Science, 74, 2724-2736 (1999).

[18] Cao X., Lee L. J., Widya T., Macosko C.: Polyurethane/clay nanocomposites foams: Processing, structure and properties. Polymer, 46, 775-783 (2005).

[19] Xu Z., Tang X., Gu A., Fang Z.: Novel preparation and mechanical properties of rigid polyurethane foam/ organoclay nanocomposites. Journal of Applied Polymer Science, 106, 439-447 (2007).

[20] Modesti M., Lorenzetti A., Besco S.: Influence of nanofillers on thermal insulating properties of polyurethane nanocomposites foams. Polymer Engineering and Science, 47, 1351-1358 (2007).

[21] Yang Z-G., Zhao B., Qin S-L., Hu Z-F., Jin Z-K., Wang J-H.: Study on the mechanical properties of hybrid reinforced rigid polyurethane composite foam. Journal of Applied Polymer Science, 92, 1493-1500 (2004).

[22] Krupers M. J., Bartelink C. F., Grünhauer H., Moller M.: Formation of rigid polyurethane foams with semifluorinated diblock copolymeric surfactants. Polymer, 39, 2049-2053 (1998).

[23] Gedde U. W.: Polymer physics. Chapman and Hall, London (1995).

[24] Niyogi D., Kumar R., Gandhi K. S.: Water blown free rise polyurethane foams. Polymer Engineering and Science, 39, 199-209 (1999).

[25] Bird R. B., Stewart W. E., Lightfoot E. N.: Transport phenomena. Wiley, New York (2006).

[26] Wu J-W., Sung W-F., Chu H-S.: Thermal conductivity of polyurethane foams. International Journal of Heat and Mass Transfer, 42, 2211-2217 (1999). 